\title{
Erratum to: Life could be so easy: the convenience effect of round price endings
}

\author{
Jan Wieseke • Anika Kolberg • Laura Marie Schons
}

Published online: 18 March 2015

(C) Academy of Marketing Science 2015

Erratum to: J. of the Acad. Mark. Sci.

DOI 10.1007/s11747-015-0428-7

Table 3 in the original version of this article contained mistakes in the last column, where a single asterisk was used instead of three asterisks. The correct table is shown below:

The online version of the original article can be found at http://dx.doi.org/ 10.1007/s11747-015-0428-7.

J. Wieseke $(\square)$

Ruhr-University Bochum, GC 4/162, 44780 Bochum, Germany

e-mail: jan.wieseke@rub.de

\footnotetext{
A. Kolberg

Ruhr-University Bochum, GC 4/157, 44780 Bochum, Germany

e-mail: anika.kolberg@rub.de

L. M. Schons

Ruhr-University Bochum, GC 04/150, 44780 Bochum, Germany

e-mail: laura.schons@rub.de
} 


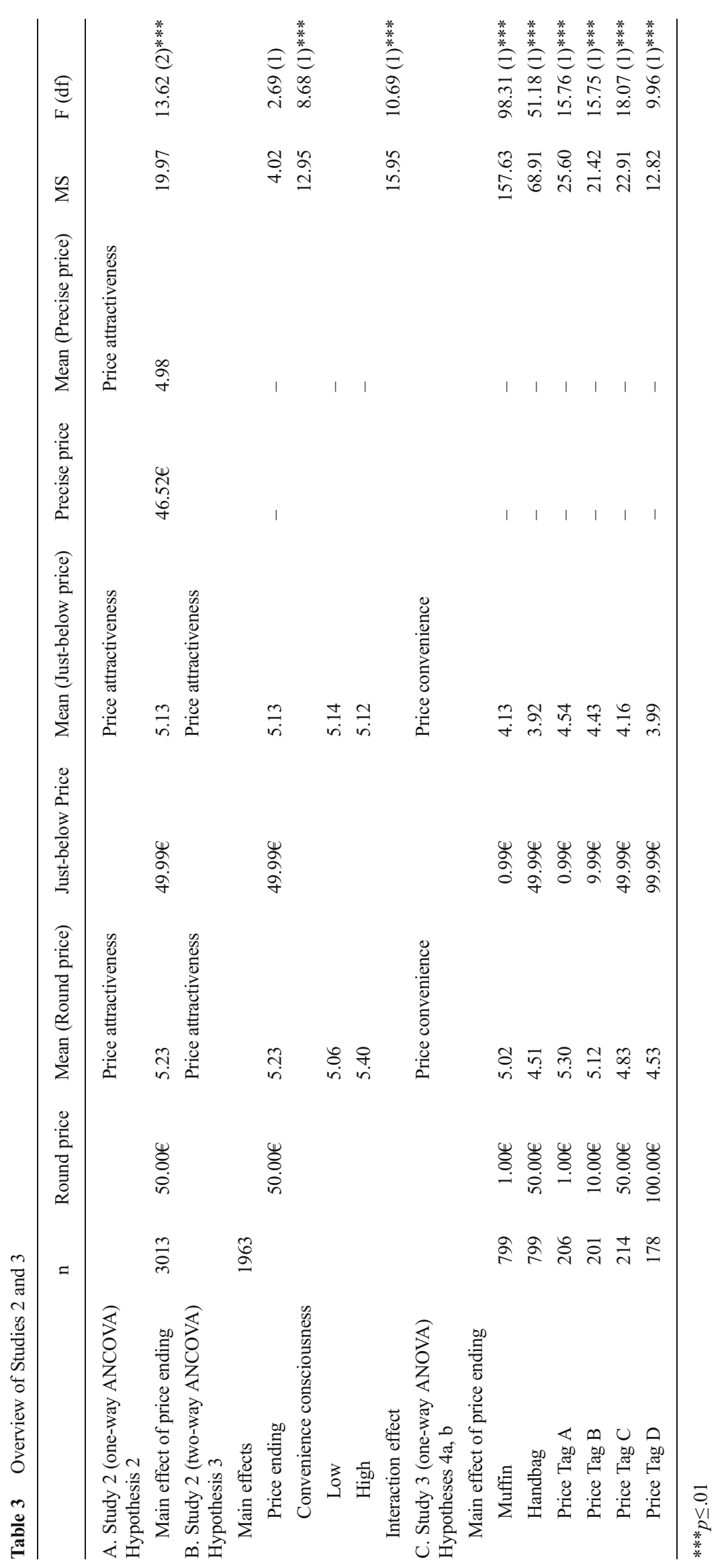

